be tolerably even. It is advisable to have the ground next the curb well trodden on and rammed before the pavement is laid, otherwise there will be an unseemly hollow next the curb. In laying, the rough stuff is put down first and rolled tolerably firm, then the second quality is put on, then the third, and when the whole has been raked level, a little of the finest material is sifted on through a sieve with $\frac{1}{8}-$ in. meshes, and a litlle fine white shingle or Derbyshire spar is sprinkled on the top. The whole must now be well rolled. The best roller is a water ballast roller, which at first is used without ballast, and well wetted to prevent adhesion of the material, and, when the pavement is slightly consolidated, the full weight should be applied.

For heavy cart traffic the material should be made of shingle only, heated and mixed as above, and well rolled. Both descriptions of parement are laid best and most easily in warm weather, and should be rolled when the sun has warmed it well. Those parts in angles should be well rammed and trimmed off with a light shovel.

Though apparently a simple manufacture, there is a little difficulty in ascertaining the proportion of tar to gravel or cinder-dirt. A little experience will only be necessary in this, as well as in all other manufactures, to enable anyone to carry it out successfully.

This pavement cannot be spoken of too highly, as it is cheap, wears well, and can be easily repaired. The colour, which never can be made to equal York flag, and the smell for some time after it is laid, are the only objections to its use ; it can be laid with a good profit in any district at $\mathrm{I} s .4 d$. per square yard; and besides being a boon to the public, who must otherwise walk on gravel, is a great advantage to gas companies. To them it provides a remunerative outlet for their tar, which often otherwise must be sold at a low price to distant distillers.

A late paragraph, which appeared in the daily press, states that it is proposed to pave the streets of London with stone laid in asphalte instead of lime grout. This is just a more systematic application of the above-described plan; for the tar, by being boiled and thrown on hot stones, becomes an elastic asphalte.

\section{INDIAN BARRACKS}

$\mathrm{R}^{\mathrm{E}}$ CENT discussions regarding the new Indian Barracks have shown the necessity for an adequate knowledge of physical science on the part of all engineers who have to cope with great natural forces.

These costly structures have been described as "sun traps," meaning thereby that the materials and details have been so selected, that instead of the interior of the rooms being as cool as, if not cooler, than the outside, it is cooler for the men to be in the open air under the sun. It is true that this objection has been raised at very few stations, but with adequate knowledge on the part of the architects, it ought never to have been raised at all. The barracks complained of are stated to be brick structures of the usual dark colour, with verandahs supported not on light easily heated and easily cooled columns, but on massive piers and arches like a bridge. The roofs have been constructed almost as they would have been at home, and no adequate means have been adopted for protecting the walls from sun-radiation. Of course the great mass of brickwork becomes heated during the day, and heats the air outside and inside the rooms at night, while the structure of the roof is such that the interior is heated both by direct conduction and radiation. Now surely such mistakes might have been avoided. There are such things as nonconducting materials to be had, and double walls with a ventilating air space between are not an uncommon expedient in this country for keeping out both heat and cold. Again, there is such a thing as white plaster or whitewash for outside walls, which reflects a large portion of the solar heat. Double roofs are not unknown, we believe, in India, and it is possible to construct such a roof as to interpose not only an air current between the outer and inner layer of the roof, but to prevent the radiation of the inner surface of the outer layer passing through the inner layer. These are very elementary applications of physical laws to Indian house construction, and how little they have been attended to may be inferred from a fact which has been stated-viz., that these barracks have been roofed with slate. The ordinary laws of conduction and radiation of heat appear to be at a discount in the Indian works department.

\section{THE PROVINCE OF MINERAL CHEMISTRY}

PROFESSOR KOLBE has recently succeeded to the directorship of the fournal fiur Praktische Chemie, rendered vacant by the decease of Erdmann, its original founder; and in his hands this periodical will doubtless become the recognised organ of the modern Leipsic School of Chemistry. Dr. Kolbe, in the first number 0 the new series of this work, has signalised his succession to the office of editor by an introductory essay, seiting forth his opinions upon what he considers must be the future aim of the student of Inorganic Chemistry. Organic Chemistry, once the neglected sister of Inorganic Chemistry (to use the Professor's phraseology), has become so courted and honoured since Liebig introduced her as a young science into the chemical world, that little by little her relative has sunk into comparative obscurity. But the time has now arrived when, in Kolbe's opinion, it is evident that Inorganic Chemistry has not merited this neglect, but that she has it in her power to bestow rewards not less precious than those of Organic Chemistry, upon those who devote themselves to her service.

Much of the attractiveness of Organic Chemistry must, according to Kolbe, be traced to the zeal with which the origin of the almost numberless cases of Isomerism in organic compounds is being searched out; indeed, this zeal has nearly displaced the lively interest in Inorganic Chemistry created by the discovery of Isomorphism. This cause can never actuate the investigator in the domain of Inorganic Chemistry-at least not to the same extent-and for the reason adduced by Kolbe, that Isomerism cannot possibly occur in inorganic compounds to anything like the same degree as among organic substances, owing to the greater simplicity of constitution possessed by the former class. That so few cases of Isomerism have been discovered in Inorganic Chemistry is undoubtedly due to the fact that hitherto we have neglected to investigate mineral substances with special regard to their chemical constitution.

In order to prove the truth of this latter assertion Kolbe asks how can we frame anything like a reply to any question respecting the chemical constitution of the naturallyoccurring silicates-felspar, for example? What are the proximate constituents of this compound, and what are their respective functions?

In half a dozen brief sentences Kolbe disposes of all our knowledge upon this subject, beginning with the views of Berzelius, by whom felspar-the typical silicate-was regarded as possessing a constitution analogous to that of dehydrated alum-that is, as a double salt of neutral silicate of alumina and silicate of potash; and ending with Gerhardt, who thought to explain the constitution of this and all bodies by his theory of types, or, in the expressive language of Professor Kolbe- "mit de1 mechanischen Handhabung eines todten Schematismus."

The greater portion of the paper is devoted to Kolbe's theoretical views upon the nature of felspar, and he suggests a number of structural formulæ to explain its constitution according to our present opinions upon the quantivalence of the component elements. Whether, however, any of these formulæ represent the actual con- 